\title{
Computational Studies on the Reaction between Monoethanolamine and Nitrogen Oxides
}

\author{
Jae-Goo Shim, Jun-Han Kim, Young H. Jhon,, " and Jaheon Kim ${ }^{+}, "$

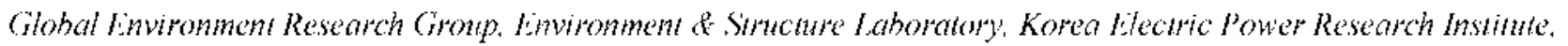 \\ Daejeon 305-380. Korea

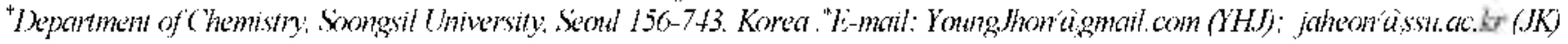 \\ Received September +. 2009. Accepted October 28, 2009
}

Key Words: Nitrogen oxides, Monocthanolamine. Reaction. Transition state, DFT

The flue gas emitted by power plants is composed of mainly $\mathrm{N}_{2}$ and $\mathrm{CO}_{2}$ with a small amount of the harmful gases $\mathrm{SO}_{2}$ and $\mathrm{NO}_{2}$. The grecnhouse gas $\mathrm{CO}_{2}$ is removed by absoption process using alkanolamines such as monocthanolamine (MEA). ${ }^{\prime}$ $\mathrm{SO}_{3}$ can also be captured by forming a Lewis acid-base complex with amincs. ${ }^{2}$ Whilc both $\mathrm{CO}_{2}$ and $\mathrm{SO}_{2}$ can form stable adducts with MEA. it should be expected that $\mathrm{NO}_{2}$ would behave differently since it is a paramagnetic gas, and in equilibrium with $\mathrm{N}_{2} \mathrm{O}_{4}$ at ambient temperature. It is possible for MEA to react with $\mathrm{N}_{2} \mathrm{O}_{4}$, too. There are patent reports on the removal of $\mathrm{NO}_{2}$ by amines. "However, no research has yet been reported on the mechanism of the $\mathrm{NO}_{2}$ climination reaction by amines. which motivated us to investigate the reaction beiween $\mathrm{NO}_{2}$ and $\mathrm{MEA}$ by quantum mechanical calculations.

As MEA can reacl with both $\mathrm{NO}_{2}$ and $\mathrm{N}_{2} \mathrm{O}_{+}$possible reaclions are classified as shown in Scheme l: (1) MEA- $\mathrm{NO}$ zor MEA- $\mathrm{N}_{2} \mathrm{O}_{4}$ complex formation, and (2) dissociation of $\mathrm{N}_{2} \mathrm{O}_{1}$ by MEA to $\mathrm{HO}\left(\mathrm{CH}_{2}\right)_{2} \mathrm{~N}-\mathrm{NO}_{2}$ and nitrous acid. $\mathrm{N}_{2} \mathrm{O}_{4}$ a planar structure wilh $\mathrm{D}_{2 \mathrm{~h}}$ symmetry has a long and weak $\mathrm{N}-\mathrm{N}$ bond in which $d(\mathrm{~N}-\mathrm{N})$ is $1.75 \mathrm{~A}$. Its dissociation energy is only 57 $\mathrm{kJ} / \mathrm{mol}(13.6 \mathrm{kcal} / \mathrm{mol}){ }^{+}{ }^{+} \mathrm{N}_{2} \mathrm{O}_{4}$ is casily hydrolyed to produce $\mathrm{H}_{3} \mathrm{NO}_{3}$ and $\mathrm{HNO}_{2}$. As it is. it is expected that MEA could also break the $N-N$ bond by an $S \backslash 2$ type reaction.

In this work all calculations were carricd out using the Gaussian 03 suitc of programs. "Goometry optimization and energy. calculations were performed on the computational level of Hartrec-Fock. and density functional theory (DFT) with the B3LYP functional, respectively: For the energy calculation, we used the aqucous solyation model. PCM, developed by Tomasi $c t a l^{\prime}$ The adopted basis set was 6-31 + G(d.p), and the car ities of the solvation model were given Bondi radii."

Optimization and energ calculations for the MEA-NO= complex yielded a positive Gibbs energy: $+7.6 \mathrm{kcal} / \mathrm{mol}$. Although there are some stable compounds having an N-NO? bond? ${ }^{?-11}$ the MEA-NO 2 complex is not likely to form spontancously: Similarly; the $\mathrm{MEA}-\mathrm{N}_{2} \mathrm{O}_{4}$ complex was verv unstable, and each species was separated. and did not form a chemical bond during calculations.

As both $\mathrm{NO}_{2}$ and $\mathrm{N}_{2} \mathrm{O}_{4}$ cannot form stable complexes with MEA, a nucleophilic reaction between MEA and $\mathrm{N}_{3} \mathrm{O}_{4}$ was investigated. The reaction pathway for a reaction between MEA and $\mathrm{N}_{2} \mathrm{O}_{-}$is monitored by a "coordinate driving" method, ${ }^{12.1 ?}$ with a key parameter being $d(\mathrm{~N}-\mathrm{N})$, a distance between

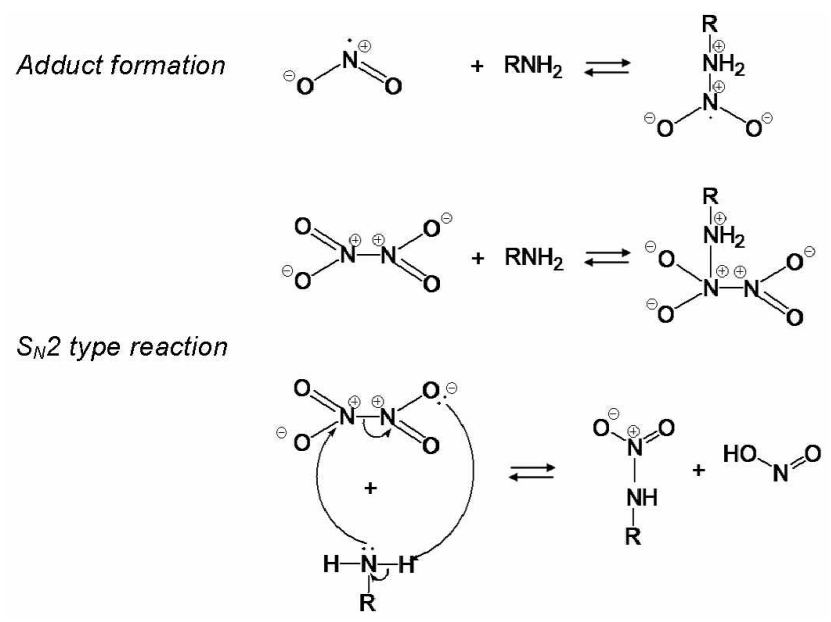

Scheme 1. Reactions considered in this notk are displared with

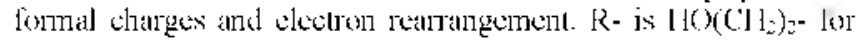
$\mathrm{MH} / \Lambda$

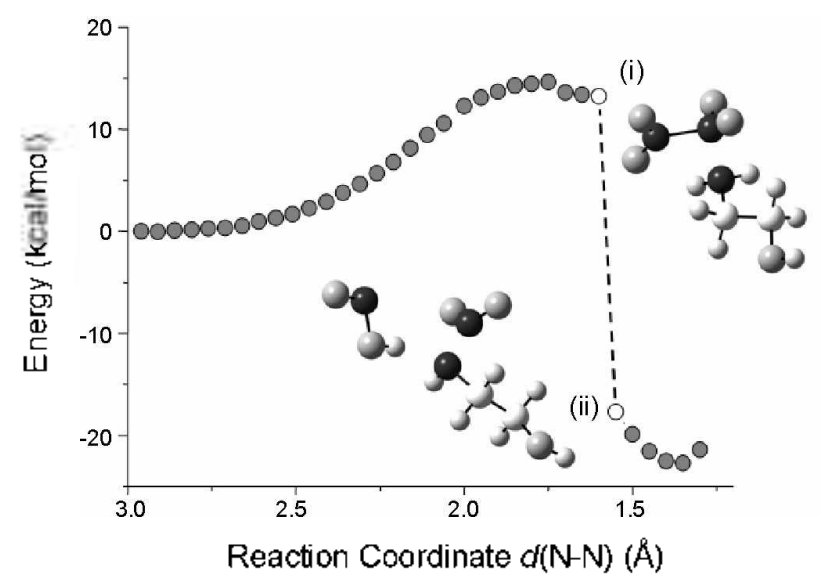

Figure 1. linerg is reaction cordinate $d(\mathrm{~N}-\mathrm{N})$ for the reaction between $\mathrm{Ml}: \Lambda$ and $\mathrm{N}_{2}\left(\mathrm{O}_{12}\right.$, which preduces $\mathrm{I} \mathrm{JNO}_{3}+\mathrm{IJO}\left(\mathrm{CH} \mathrm{I}_{2}\right)_{2} \mathrm{NI} \mathrm{J}-$ $\lambda()_{2}$. There is a diseontinuous change between the joints (i), comtespending to preudo- $I S$, and (ii), a product.

the nitrogen atom in MEA and a nitrogen atom in $\mathrm{N}_{2} \mathrm{O}_{4}$, as shown in Figure 1. The value of $d(\mathrm{~N}-\mathrm{N})$ was fixed to $3.07 \mathrm{~A}$. and all other geometric parameters were optimized. In this manner the encrgy profile was oblained by reducing $d(\mathrm{~N}-\mathrm{N})$ 
Table 1. Selected inter-atomic distances of the $\mathrm{N}_{2} \mathrm{O}_{4}-\mathrm{MEA}$ complexes

\begin{tabular}{ccccc}
\hline distance $(\AA)$ & Teactants & Psendo-TS & TS & products \\
\hline$d(\mathrm{~N}-\mathrm{N})$ & 2.99 & 1.75 & 1.60 & 1.33 \\
$d(\mathrm{~N}-\mathrm{N})^{\circ}$ & 1.57 & 1.62 & 1.81 & 3.70 \\
$d(\mathrm{O}-\mathrm{H})$ & 3.09 & 2.39 & 1.98 & 0.95 \\
\hline
\end{tabular}

(a)

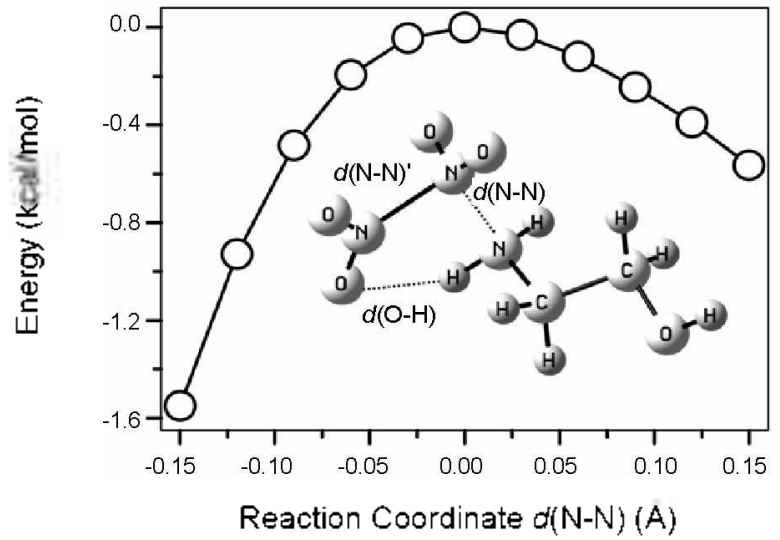

(b)

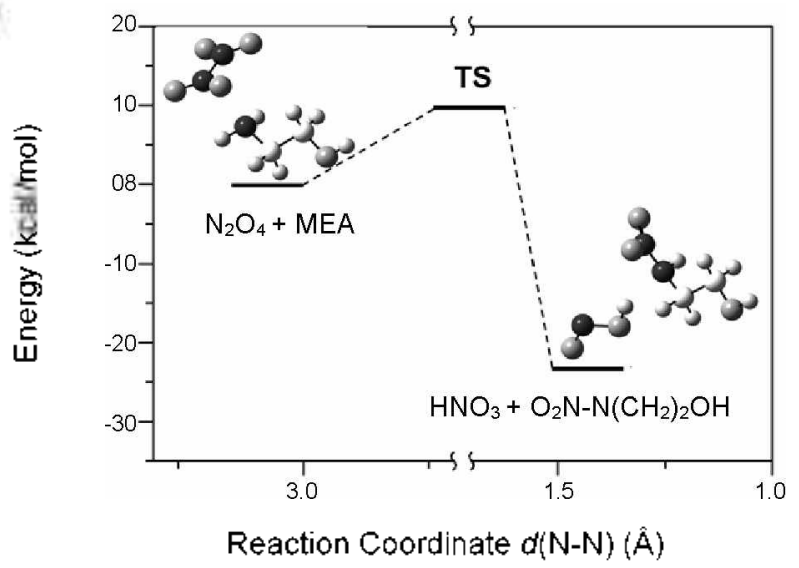

Figure 2. (a) IRC plot around TS, and (b) energies for the reactants, $\mathrm{TS}$, and products for the reaction between $M E A$ and $\mathrm{N}_{2} \mathrm{O}_{4}$.

to $1.2 \AA$. The resulting relative energies are plotted against the reaction coordinate. The energy of the initial optimized chemical strncture with the fixed key parameter is defined as zero. The reaction was involved with one energy barrier at $1.75 \mathrm{~A}$. When $d(\mathrm{~N}-\mathrm{N})$ was reduced further above the pseudo-TS (transition state), and the chemical connectivity of the system was changed greatly at $1.55 \sim 1.6$ A. the energy dropped from 13.3 $\mathrm{kcal} / \mathrm{mol}$ to $-17.7 \mathrm{kcal} / \mathrm{mol}$. This unusual result indicated that the reaction coordinate and the application of the "coordinate driving" method to this work was not pertinent. or needed other factors to make it so. ${ }^{14}$

Instead of monitoring the reaction profile. the transition state (TS) was determined using the pseudo-TS structure obtained by the coordinate-driving method. The obtained TS structure (Figure 2a) had only one negative eigenvalue, corresponding to an imaginary vibration of $2292.4 \mathrm{~cm}^{-1}$ along the line connecting two reacting $\mathrm{N}$ atonss. Intrinsic reaction coordinate (IRC) calculations performed at ten points around the TS confirmed that the energy values at these points were lower than that of the TS (Figure 2a). ${ }^{5}$ The energy' r.s. reaction coordinate is plotted in Figure $2 b$; here, structures for reactants. TS, and products, are displayed. The activation energy was 9.7 $\mathrm{kcal} / \mathrm{mol}$. Optimization and energy calculations were also carried out for both reactants and products. The calculated reaction energy was $-22.5 \mathrm{kcal} / \mathrm{mol}$, showing that the proposed reaction is spontaneous. Vibrational frequency analyses showed that all the stationary points of the reaction models had no imaginary frequencies. which confirmed that the obtained geometries were at their energy minima.

The important interatomic distance changes of $d(\mathrm{~N}-\mathrm{N})$. $d(\mathrm{~N}-\mathrm{N}) '$. and $d(\mathrm{O}-\mathrm{H})$ (Figure 2a). the distances of the bonds which are formed or broken during the reaction, are listed in Table 1. It is seen that $\mathrm{N}_{2} \mathrm{O}_{4}$ maintains its structure with $d(\mathrm{~N}-\mathrm{N})^{\prime}$ a little elongated at TS, while MEA and $\mathrm{N}_{2} \mathrm{O}_{4}$ are partially bonded, with $d(\mathrm{~N}-\mathrm{N})=1.33 \mathrm{~A}$. It is also found that the $\mathrm{H}$ atom in MEA transferred to the oxygen atom in $\mathrm{N}_{2} \mathrm{O}_{4}$ to produce a nitrous acid. $\mathrm{HNO}_{2}$.

In short. $\mathrm{NO}_{2}$ seems to be eliminated in a fundamentally different mauner from $\mathrm{CO}_{2}$ and $\mathrm{SO}_{2}$. While these two gases form stable adducts. $\mathrm{NO}_{2}$ can be renoved indirectly by an $\mathrm{N}_{2} \mathrm{O}_{4}$ elimination pathway. It is possible that $\mathrm{NO}_{2}$ is also elininated by $\mathrm{H}_{2} \mathrm{O}$ to give nitiric acid. ${ }^{15}$ and $\mathrm{N}_{2} \mathrm{O}_{5}$, like $\mathrm{N}_{2} \mathrm{O}_{4}$, can react with MEA. For the latter case. the only difference is that nitric acid rather than nitrous acid is produced: in all, the computed reaction energy was $-43.8 \mathrm{kcal} / \mathrm{mol}$.

Acknowledgments. This work was supported by the KEMCO (Korea Energy Management Corporation).

\section{References}

1. Shim, T.: Kim, I.: Thon, Y. H.: Kim, J.; Cho, K. Ind Eng. Chem Res. $2009,+8,2172$

2. Shim, J., Thon, Y. H.; Kim, J., Jang, K.; Kim, I. Bull Konean Chem. Soc. 2007, 28, 1609 .

3. (a) Paczkowski, M. M. U.S. Patent 3846981, 1974. (b) Epperly, W. R. U.S. Patent 4863705,1989 . (c) Pooler. I. U.S. Patent 6945925 , 2005 .

4. Cotton, F. A.; Wilkinson, G.; Gaus, P. L. Basic Morganic Chentism, 2nd edition. J. Wiley \& Sons: N. Y. 1987.

5. Foresman, J. B.; Frisch, E. Exploning Chemisty with Electronic Strtcture 1/thods: Gaussian Inc.: Pittsburgh, 1996.

6. Lee, C.; Yang, W.; Part, R. G. Phus. Rev. B 1988, 37,785

7. Miertus, S.; Scrocco, E.; Tomasi, T. Chem. Phys. 1981, $55,117$.

8. Bondi. A.J. Phys. Chent 1964, 68,441.

9. Turley, J. W. Acta Cinstallogr., Sect B: Snnct. Cnstallogi: Cinst. Chem. 1968, 24, 942 .

10. Butcher, R. J.; Giardi, R. D.; George, C.; Flippent-Anderson, J. J. Chem. Crust 1996, 26, 381.

11. Vasil'ev, A. D.; Astakhov, A. M.; Krugllyakova, L. A.; Stepanov, R. S. Zh. Striht. Khim. 2002, $43,954$.

12. Zhang. Y.: Liu, H.: Yang, W. J. Chem. Phus 2000, 112, 3483.

13. Young, D. C. Computational Chentistry, A Tohn-Wiley \& Sons, Inc.: 2001 .

14. Toney, M. D. Biochemistov 2001, $\$ 0,1378$.

15. $\mathrm{As} \mathrm{a} \mathrm{CO}_{2}$ absorption process using alkanolamine operates at 40 $60^{\circ} \mathrm{C}$, the reaction between $\mathrm{NO}$, and $\mathrm{H}_{3} \mathrm{O}$ was cal culated at $50^{\circ} \mathrm{C}$ and $25^{\circ} \mathrm{C}$, respectively. The energies were almost the same, with $-0.46 \mathrm{kcal} / \mathrm{mol}$ at $50^{\circ} \mathrm{C}$, and $-0.43 \mathrm{kcal} / \mathrm{mol}$ at $25^{\circ} \mathrm{C}$. In a real $\mathrm{CO}_{2}$-absorption process, amines are used as an aqueous solution. As it is, $\mathrm{NO}_{2}$ elimination may take place competitively by amines and water. 